\title{
Micropolítica do trabalho na Estratégia Saúde da Família: quem cuida também precisa de cuidados?
}

\author{
Micropolitics of the work in the Brazilian Family Health Program: \\ do caretakers also need care? \\ Micropolitica del trabajo en la Estrategia de Salud de la Familia: \\ ¿los cuidadores también necesitan atención? \\ Francisco Senna de Oliveira Neto
}

\section{Palavras-chave: \\ Saúde Pública Atenção Primária à Saúde \\ Saúde da Família Saúde do Trabalhador}

Keywords: Public Health Primary Health Care Family Health Occupational Health

\section{Resumo}

0 espaço da micropolítica do trabalho na Estratégia Saúde da Família (ESF) traduz-se no cenário em que transcorre o protagonismo dos trabalhadores e usuários dos serviços de saúde. Este artigo objetivou reconhecer e estudar o potencial diverso, criativo e dinâmico do modo como se organiza a atividade produtiva em saúde na ESF e, em especial, lançar um olhar sobre a outra face da tecnologia do cuidado: a saúde do trabalhador/cuidador. Trata-se de um estudo de caráter exploratório, quali-quantitativo, que foi desenvolvido a partir da aplicação de instrumentos de avaliação da qualidade de vida e anamnese ocupacional, e também apoiado na observação e avaliação do cotidiano de trabalho em uma Unidade de Saúde da Família, do município de Jerônimo Monteiro, no Espírito Santo. Os resultados demonstram que, quando se refere à própria saúde, o trabalhador/cuidador preocupa-se mais com problemas e agravos de saúde já instalados, negligenciando os aspectos preventivos. Sinais de sofrimento orgânico e psíquico constituíram registros da sobrecarga laboral e da precariedade dos vínculos e das condições de trabalho. 0 estudo apontou, ainda, que merecem ser feitas reflexões sobre a saúde ocupacional na ESF e que a prevenção e a promoção da saúde precisam ser 'exercitadas' também pelos trabalhadores. Faz-se necessário rever os caminhos da ESF sob a ótica da Saúde do Trabalhador, rumo à construção dos ambientes de trabalho humanizados e humanizadores.

\section{Abstract}

The space of work micropolitics in the Brazilian Family Health Strategy is a scenario where the protagonism of workers and users of health services takes place. The objective of this article was to recognize and study the diverse, creative, and dynamic potential of how the activities in the Brazilian Family Health Strategy are organized and, mainly, to see the other face of the health care technology: the health of the health workers. This is a qualiquantitative exploratory study, developed by the application of instruments for the evaluation of life quality and occupational history, supported by the observation and evaluation of the daily work in a Brazilian Family Health Strategy unit in the town of Jerônimo Monteiro, state of Espírito Santo, in Brazil. The results show that, when targeting his/her own health, the health worker is more concerned about health problems and disorders already installed, neglecting the preventive aspects. Signs of organic and psychic suffering were considered as caused by work overload and by precariousness of links and work conditions. The study also showed that reflections on occupational health in the Brazilian Family Health Strategy also need to be carried out and that health prevention and promotion need to be explored by health workers. It is also important to review the path of the Brazilian Family Health Strategy under the perspective of health workers, aiming at the construction of a humanized work environment.

'ESF de Jerônimo Monteiro - Jerônimo Monteiro (ES), Brasil. cenna@terra.com.br

Fonte de financiamento: nenhuma.

Conflito de interesses: declarou não haver.

Recebido em: 17/02/2011

Aprovado em: 09/12/2011 


\begin{abstract}
Palabras clave:
Salud Pública

Atención Primaria de Salud

Salud de La Familia

Salud Laboral

\section{Resumen}

El espacio de la micropolítica del trabajo en la Estrategia Brasileña de Salud de la Familia se refleja en el escenario donde se desarrolla el papel principal de los trabajadores y usuarios de los servicios de salud. Este artículo tuvo como objetivo reconocer y estudiar el potencial de la diversidad, creativa y dinámica de la forma de organizar la actividad productiva en materia de salud en la Estrategia Brasileña de Salud de la Familia y, en particular, pone la mirada en el otro lado de la tecnología de lo cuidado de la salud: los trabajadores/cuidadores de la salud. Este es un estudio exploratorio de cualitativos y cuantitativos, desarrollados a partir de la aplicación de herramientas para evaluar la calidad de vida y la historia ocupacional, y también apoyó la observación y evaluación del trabajo diario en una Unidad de Salud de la Familia de la Ciudad de Jerónimo Monteiro, en Espírito Santo. Los resultados muestran que, en referencia a su salud, los trabajadores/cuidadores están más preocupados por los problemas de salud y los trastornos que ya están instalados, dejando de lado los aspectos preventivos. Los signos de sufrimiento orgánico y psicológico constituyen registros de una sobrecarga de trabajo y de la precariedad y inseguridad de los vínculos y de las condiciones de trabajo. El estudio también muestra que reflexiones deben hacerse sobre la salud en el trabajo en la Estrategia Brasileña de Salud de la Familia, y que la prevención y promoción de la salud deben ser 'ejercidas' por los trabajadores. Es necesario revisar también las formas de la Estrategia Brasileña de Salud de la Familia desde la perspectiva de la salud en el trabajo, hacia la construcción de un entorno de trabajo humanizado y humanizante.
\end{abstract}

\section{Introdução}

\section{A implantação da Estratégia Saúde da Família em Jerônimo Monteiro}

Diferentes momentos da história da saúde pública registram referências à unidade familiar enquanto objeto de intervenção em saúde, numa perspectiva de organização da atenção à saúde com foco no usuário, em sua família e na comunidade.

Na década de 1990, foram instituídos, pelo Ministério da Saúde (MS), os Programas de Agentes Comunitários de Saúde (PACS) e de Saúde da Família (PSF), apresentados como caminhos para a reorientação das práticas de atenção à saúde ${ }^{1}$. O PSF, posteriormente nominado Estratégia Saúde da Família (ESF), inovou ao constituir uma equipe multiprofissional no primeiro nível de contato com os serviços de saúde ${ }^{1,2}$. Os impactos positivos e a significação social dessa proposta sobre a organização dos serviços e qualidade de saúde e de vida das pessoas constituem-se em justificativa mais que suficiente para avançar na pavimentação desses caminhos ${ }^{3-5}$.

Passados 12 anos da implementação das equipes de ESF no município de Jerônimo Monteiro, no Espírito Santo, é possível contabilizar e visualizar tal processo a partir das significativas mudanças determinadas nas condições de saúde da população. O município avançou rapidamente na implantação da ESF, contando desde 2002 com cobertura de $100 \%$ (Tabela 1).

Um estudo realizado em municípios da região Sul do Estado do Espírito Santo, em 2009, retrata que o aumento da cobertura da ESF é diretamente proporcional à melhoria dos indicadores de saúde e da ampliação do acesso aos serviços de saúde, numa perspectiva de inclusão social e democratização das práticas e do cuidado ${ }^{6}$.
Inicialmente estruturadas sem muito planejamento e critérios definidos e com incipiente participação da comunidade, as Unidades de Saúde da Família foram brotando com seus muitos compromissos. Unidades de saúde tradicionais, e mesmo casas alugadas, foram adaptadas, para dar lugar à nova proposta em construção. Os recursos humanos também foram adaptados.

$\mathrm{O}$ estudo se justifica na medida em que a ESF avança como projeto estruturante e norteador do Sistema Único de Saúde (SUS), com caráter substitutivo das unidades tradicionais de saúde e, com isso, incorpora a cada dia quantitativo maior ao 'exército' de trabalhadores. Além disso, ainda são restritas as abordagens sobre a organização e a gestão do trabalho em saúde no Espírito Santo, estado que já conta com 570 equipes de ESF implantadas, correspondendo a uma cobertura populacional de $52 \%^{7}$. Estes profissionais da saúde encontram-se imbuídos da missão sanitária de 'cuidar de tudo e de todos' dentro de seu território e, por não apresentarem 'plenos poderes', sofrem diante dos limites concretos, institucionais ou não, e, diante de tantos regulamentos, cobranças e exigências, vão perdendo o poder resiliente. Com isso, adoecem, 'de corpo e alma's.

\section{Olhares sobre a micropolítica do trabalho na ESF}

Enquanto a Saúde da Família consolida-se como principal estratégia de organização da Atenção Primária à Saúde (APS) no Brasil e avança na cobertura de cada vez mais milhões de brasileiros, o contingente de trabalhadores também expressivo do SUS debruça-se, diuturnamente, a desenvolver e aprimorar as ações de atenção à saúde.

O espaço da micropolítica do trabalho na ESF traduz-se, assim, no cenário em que transcorre o protagonismo dos 
trabalhadores e usuários dos serviços de saúde. Constrói-se, portanto, múltiplo de quantas identidades se inscreverem no contexto como coletivo de sujeitos, que possuem modos próprios de ver, interpretar e atuar no mundo e que pretendem realizar seus projetos.

O ambiente do trabalho na ESF também revela relações de poder e disputa, e prevê a construção de microrredes, nas quais formalizam-se microprocessos, que se organizam por meio dessas relações, revelando estruturas extremamente complexas, social e subjetivamente determinadas?.

A identidade, o ethos do ambiente de trabalho em saúde, constitui, assim, um mundo próprio, rico, complexo, diverso, criativo, dinâmico, não-estruturado e de alta possibilidade inventiva e transformadora. É o protagonismo de trabalhadores e usuários dos serviços de saúde, sujeitos interdependentes nos seus espaços de trabalho e nas relações, guiados por diversos interesses, pelo encontro com finalidades, pela intencionalidade vinculada ao seu modo de ser, à sua subjetividade, os quais organizam suas práticas e ações em saúde ${ }^{10,11}$. O campo da micropolítica do trabalho em saúde, portanto, está sempre ligado ao encontro, à característica relacional, como um sistema aberto.

Como percebe-se, muitas são as conexões e interações que se processam na produção da saúde. A interdisciplinaridade significa integração, interdependência e complementaridade dos múltiplos saberes, direcionados para a construção de alternativas planejadas de intervenção sobre os problemas de saúde, considerando os múltiplos condicionantes e determinantes do processo saúde-doença-cuidado e os indivíduos como sujeitos, que são capazes de experimentar soluções para seus próprios problemas, e construção/produção da sua própria saúde ${ }^{12}$.

Vale ressaltar que os profissionais Médicos de Família e Comunidade são às vezes desestimulados a ingressar na especialidade em virtude da falta de reconhecimento da mesma, seja pela população ou por colegas de profissão, ou em virtude das imagens distorcidas da especialização nessa área, adquiridas ao longo da graduação ${ }^{13}$. Além disso, essa especialidade, a cuja responsabilidade são designados os cuidados primários em saúde, ainda tem sido associada à baixa resolutividade, aos limitados recursos de conhecimento técnico-científico, e até mesmo à baixa qualidade e insuficiente tecnologia de cuidados ${ }^{14,15}$. Registre-se, também, o ainda reduzido número de médicos especialistas em Medicina de Família e Comunidade, titulados pela Sociedade Brasileira de Medicina de Família e Comunidade (SBMFC) ${ }^{16}$.

Com relação aos enfermeiros, a situação faz-se inversa. Estudo recente realizado no Sul do estado do Espírito Santo aponta saturação do mercado de trabalho na ESF para estes
Tabela 1. Evolução da cobertura de PACs, PSF e ESB, por ano, no Município de Jerônimo Monteiro - período de 1998 a 20097.

\begin{tabular}{lccccc}
\hline Ano & $\begin{array}{c}\mathrm{N}^{0} \text { de ACS } \\
\text { implantados }\end{array}$ & $\begin{array}{c}\text { \% de cobertura } \\
\text { populacional ACS }\end{array}$ & $\begin{array}{c}\mathrm{N}^{0} \text { de ESF } \\
\text { implantadas }\end{array}$ & $\begin{array}{c}\text { \% de cobertura } \\
\text { populacional ESF }\end{array}$ & $\begin{array}{c}\mathrm{N}^{0} \text { de ESB } \\
\text { implantadas }\end{array}$ \\
\hline 1998 & 14 & 92,9 & 1 & 35,53 & - \\
\hline 1999 & 24 & 100 & 1 & 35,53 & - \\
\hline 2000 & 22 & 100 & 1 & 34,62 & - \\
\hline 2001 & 24 & 100 & 3 & 99,98 & 1 \\
\hline 2002 & 26 & 100 & 4 & 100 & 2 \\
\hline 2003 & 26 & 100 & 4 & 100 & 2 \\
\hline 2004 & 26 & 100 & 4 & 100 & 2 \\
\hline 2005 & 26 & 100 & 4 & 100 & 3 \\
\hline 2006 & 26 & 100 & 4 & 100 & 3 \\
\hline 2007 & 26 & 100 & 4 & 100 & - \\
\hline 2008 & 26 & 100 & 4 & 100 & 2 \\
\hline 2009 & 26 & 100 & 4 & 100 & 4 \\
\hline
\end{tabular}

( - ) sem cobertura; (1) até agosto de 2009; ACS: agentes comunitários de saúde; ESF: Estratégia Saúde da Família; ESB: Estratégias de Saúde Bucal.

profissionais ${ }^{6}$. Conforme alegam alguns gestores, há uma pilha de currículos aguardando vagas, numa cristalização de verdadeiro 'exército de reservas' para a $\mathrm{ESF}^{6}$.

A precariedade com que foi edificada a relação de vínculo profissional dos trabalhadores da ESF também atua como desestímulo ao desempenho e à motivação dos $\operatorname{mesmos}^{6,14,15}$

Também norteia o processo de trabalho e constitui entrave a ser vivenciado e superado à rigidez com que são divididas as equipes de ESF, caracterizando, muitas vezes, uma barreira à oferta dos serviços de saúde. A divisão e hierarquização do trabalho e as relações profissionais e de poder dentro das próprias equipes geram dificuldades, que comprometem o fluxo e os processos de trabalho ${ }^{17}$.

Há, ainda, a necessidade de serem revistas as dimensões do processo de trabalho, numa perspectiva de romper com a concepção biopolítica que orienta a atuação e as práticas sobre as doenças e no investimento de tecnologias 'duras' inscritas no 'trabalho morto', que desarticula a potência transformadora da ESF e aprisiona as práticas de trabalho em normas e regulamentos ${ }^{18}$.

Clama por reflexão, portanto, a organização dos serviços de saúde que, na maior parte das vezes, é determinada a partir da lógica dos próprios serviços e não considera a lógica das necessidades e prioridades da comunidade.

Realmente, as dificuldades para se lidar com a dinâmica familiar e comunitária são muitas, e as suposições e o empirismo, sustentados pela experiência individual, acabam dando margem para orientar as práticas de trabalho ${ }^{19,20}$.

Enfim, como nota-se, o trabalho na ESF exige integrar a racionalidade técnica à solidariedade, as tecnologias ao ‘agir comunicativo' e as ações políticas ao vínculo afetivo com as famílias. 


\section{Tecendo o cuidado em saúde}

A compreensão dos princípios e valores da vida e o resgate da condição humana nas práticas de atenção à saúde requerem, em primeiro plano, a compreensão e o respeito ao ser humano em suas distintas formas de ser e existir, considerando suas fragilidades e vulnerabilidades ${ }^{20,21}$. O olhar que focaliza só a doença e a cura perde-se na miopia técnicocientífica do conhecimento teórico, e perpetua a distância considerada 'segura', que perpassa as ações tradicionais de atenção à saúde na atualidade.

Vencer essa concepção sujeito-objeto do trabalho em saúde, substituindo-a pela relação sujeito-sujeito, é romper com a relação de domínio sobre o outro. Esse modo de conduzir a vida produtiva, organizando-a a partir das relações, deve avançar para além num propósito de sujeitoequipe, uma vez que o mundo do trabalho em saúde assume sempre uma dimensão coletiva.

A tecnologia que permeia essas relações é o cuidado. Guiado, organizado e qualificado por processos relacionais em ato, o cuidado revela um mundo próprio, rico, complexo e social e subjetivamente determinado?.

Cuidar envolve o estabelecimento de laços e vínculos na construção de saberes e fazeres em saúde. Este envolvimento, em que o outro adquire significado, apresenta-se focado no bem-estar e na superação da dor e do sofrimento. O cuidado em saúde nos convida a enxergar as dimensões que se vinculam ao trabalhador, produtor do ato, e das relações e redes de conexões deste com seu ato produtivo, com os outros trabalhadores, com os produtos que realiza e com os possíveis 'consumidores' do que é produzido ${ }^{18,22,23}$.

A atitude do cuidado abrange, portanto, mais que atenção, zelo e desvelo, significa que o outro passa a ter significado. Portanto, também revela preocupação, inquietação e sentido de responsabilidade, na medida em que, quem cuida, sente-se envolvido e afetivamente ligado ao outro. $\mathrm{Na}$ forma de cuidado, o ser humano experiencia o sentido de valor daquilo que realmente tem importância. É a partir desse valor que emerge "a dimensão de alteridade, respeito, sacralidade, reciprocidade e complementaridade" 10 .

O conceito de dimensão 'coletiva' do ser também revela o necessário olhar integral sobre o adoecimento. Com isso, o cuidado suscita a abertura/exposição ao encontro efetivo de quem cuida com quem é cuidado, de modo a tornar possível a emergência de novos territórios de significação para ambos ${ }^{23,24}$.

Este trabalho objetivou reconhecer e estudar o potencial diverso, criativo e dinâmico do modo como se organizou e se organiza cotidianamente a atividade produtiva em saúde na ESF. Em especial, lança olhar sobre a outra face da tecnologia do cuidado, ou seja, a saúde do trabalhador que atua na Saúde da Família. Com isso, buscou responder uma questão de extrema importância: quem cuida também está precisando de cuidados?

\section{Metodologia}

Para o presente estudo, utilizou-se como cenário uma Unidade de Saúde da Família do município de Jerônimo Monteiro, localizado na Macrorregião Sul capixaba. O município de Jerônimo Monteiro apresenta 11.235 habitantes $^{7}$, com discreta preponderância feminina e situação de domicílio com predomínio urbano ${ }^{6}$

A Unidade de Saúde selecionada para o desenvolvimento deste trabalho é denominada ESF Centro e encontra-se instalada na sede do município. Seu território de cobertura abrange quatro microáreas localizadas na zona urbana e duas na rural. A população coberta em 2009, ano em que foi realizado o estudo, era de 2.783 habitantes, com 870 famílias cadastradas. Chama a atenção o quantitativo de idosos acima de 50 anos, que já ultrapassava $27 \%$ da população ${ }^{25}$.

A Unidade de Saúde foi selecionada em virtude do vínculo profissional do autor, que ali executa suas atividades profissionais como Médico de Saúde da Família. O ambiente de trabalho é, pois, fonte direta de dados e informações que o autor vivencia a partir de sua inserção profissional, enquanto observador participante ${ }^{26}$. Nessa seara, envolveu-se e se deixou envolver, inserido, deliberadamente, na realidade dos fatos, princípios, cultura e sucessões de acontecimentos que permeiam o cotidiano da comunidade e do trabalho da ESF. O fato de o observador estar face a face com os observados e participar da vida deles, no seu cenário cultural, constitui-se como parte do contexto sob observação ${ }^{26}$.

Trata-se, portanto, de um estudo de caráter exploratório qualiquantitativo, que se encontra fundamentado na observação e avaliação do cotidiano de trabalho da unidade que é foco da pesquisa.

O staff profissional da ESF Centro era composto, à época do estudo, por 13 pessoas: seis agentes comunitários de saúde - todos do sexo feminino, uma enfermeira, uma técnica de enfermagem, um médico de Família e Comunidade e uma auxiliar de serviços gerais. Na Unidade também funcionava uma equipe de Estratégia de Saúde Bucal (ESB), que era composta por uma cirurgiã dentista e uma auxiliar de saúde bucal. Uma vez na semana a Unidade também contava com o atendimento de uma nutricionista.

Os dados apresentados e discutidos foram coletados a partir da aplicação de um questionário semiestruturado de qualidade de vida, composto por 30 questões (Anexo 1). Também foram utilizadas, na pesquisa, informações capta- 
das em fichas de anamnese ocupacional, preenchidas durante a realização dos exames médicos ocupacionais periódicos dos trabalhadores da Unidade. Houve consentimento informado dos trabalhadores para a pesquisa, tanto no preenchimento do questionário quanto referente às informações retiradas do exame médico ocupacional. O projeto de pesquisa foi aprovado pelo Comitê de Ética em Pesquisa da Faculdade de Filosofia, Ciências e Letras de Alegre (FAFIA), instituição educacional à qual o autor encontrava-se vinculado como docente convidado.

\section{Resultados e discussão}

Os trabalhadores da Unidade responderam ao questionário aplicado, tendo sido todos eles, também, submetidos ao exame médico ocupacional em 2009, quando aplicou-se pela primeira vez na Prefeitura Municipal de Jerônimo Monteiro a realização de tais exames, com programação anual de sua realização nos anos subsequentes. $\mathrm{O}$ médico que procedeu tais exames ocupacionais é o autor deste trabalho, uma vez que acumula as atribuições de médico do trabalho na municipalidade.

Inicialmente faz-se importante justificar a utilização, neste estudo, da expressão trabalhador/cuidador, numa alusão aos trabalhadores da ESF. Tal identificação encontra-se pautada na concretização da responsabilização sanitária, social e cultural que a equipe de saúde assume sobre seu território de atuação. A exemplo da abordagem conduzida por Bellini ${ }^{20}$, que também propõe esta denominação, busca-se caracterizar as práticas concretas de atuação da equipe numa perspectiva não mais apenas de atuação e atenção técnica, mas de envolvimento e cuidado enquanto atitude. Tal abordagem revela a cristalização do pacto entre sujeitos que cuidam e que são cuidados, mediatizado pela responsabilidade e confiança, e não mais pela determinação, pela obrigação ou pelo dever. Nesse entrelaçar-se de diferentes viveres, emergem as concepções de sujeito-usuário e trabalhador-cuidador.

Os resultados da pesquisa revelam questões que permitem refletir e indagar sobre os limites e as capacidades da ESF em concretizar tais caminhos. Evidentemente, a revisão e ampliação das discussões acerca da organização e gestão do trabalho na ESF impõem-se nesse processo.

A tabulação dos dados consolidados dos instrumentos utilizados no estudo - questionário de qualidade de vida e ficha de anamnese ocupacional - registra elementos para nortear a implementação das necessárias intervenções em saúde do trabalhador.

Os entrevistados foram indagados quanto à intensidade com que se preocupam com sua saúde, ao que $69 \%$ responderam que se preocupam muito. Comparando as informa- ções dadas com a resposta a esta questão com a da questão seguinte, relativa ao fato de interpretar se cuidam bem da própria saúde, em que $53 \%$ dos entrevistados responderam terem deixado essa questão um pouco de lado, pode-se concluir que, apesar dos trabalhadores da ESF preocuparem-se, na grande maioria, com seu estado de saúde, os cuidados destinados a ela não têm sido priorizados.

Outro tema levantado junto aos entrevistados foi quanto às questões que dificultam a atenção com sua própria saúde, ao que responderam relacionar-se, prioritariamente, à falta de tempo (77\%) e a esquecimentos (7\%). O estudo também demonstra que, quando se referencia a própria saúde, a afirmação mais frequente assinalada pelos entrevistados registra preocupação maior com problemas e agravos de saúde já instalados, determinando a procura por serviços de saúde quando apresentam alguma sintomatologia.

Os trabalhadores também foram indagados quanto à realização de exames de rotina e a periodicidade da realização destes. Apesar de ser considerado comportamento importante por $77 \%$ dos entrevistados, $54 \%$ destes relataram que não haviam realizado exames de rotina no último ano. Evidentemente que não se pretende discutir aqui a questão relativa à corrente medicalizante hegemônica, na qual se funda a concepção da realização de exames anuais, o que se contrapõe, inclusive, aos pressupostos discutidos no artigo. Tal indagação teve por objeto tão só complementar informações acerca da frequência de procura dos serviços de saúde pelos trabalhadores da Unidade.

Outro cuidado básico com a saúde, como a aferição da pressão arterial, também confirmou-se negligenciada, sendo procedimento pouco realizado pelos componentes da equipe, cuja maioria $(69 \%)$ relata não ter aferido por não haver se sentido mal ou que só afere quando sente-se mal.

A sobrecarga de trabalho e a falta de tempo foram registradas como questões impeditivas para a realização dos procedimentos relacionados à própria saúde ou a de familiares, o que traz sentimentos de culpa a $46 \%$ dos trabalhadores.

A Tabela 2 registra os tratamentos de saúde que os trabalhadores referiram realizar em 2009. Optou-se por computar os dados provenientes das fichas de anamnese ocu-

Tabela 2. Tratamentos de saúde referidos pelos integrantes da equipe da ESF Centro - Jerônimo Monteiro, em 2009.

\begin{tabular}{lcc}
\hline Patologias/queixas & $N^{0}$ de trabalhadores & $\%$ de trabalhadores \\
\hline Hipertensão arterial & 2 & 15 \\
Gastrite & 3 & 23 \\
Depressão & 2 & 15 \\
Ansiedade & 2 & 15 \\
Insônia & 1 & 7 \\
Quadro dermatológico & 2 & 15 \\
Nenhuma patologia ou queixa & 3 & 23
\end{tabular}


pacional, uma vez que tais informações encontram-se mais detalhadas neste instrumento. Como pode-se observar, ansiedade, insônia, gastrite, depressão, quadro dermatológico e hipertensão arterial figuram entre as patologias/queixas identificadas. Importante se faz ressaltar que dois trabalhadores referiram mais de uma queixa - um relatou hipertensão arterial e gastrite e o outro, ansiedade e insônia. Entre os trabalhadores investigados, $23 \%$ relataram não haver apresentado nenhuma patologia ou queixa relacionada a tratamentos de saúde em 2009.

Quanto à natureza dos desgastes determinados pelas condições de trabalho, $84 \%$ da equipe informaram que são tanto de natureza física como emocional. Os sinais de sofrimento psíquico relacionado ao trabalho são computados por $69 \%$ dos trabalhadores, os quais revelam sentimentos de tristeza, angústia, medo, irritação, nervosismo e impaciência como os mais frequentes. Além disso, cefaleias, dores em membros inferiores, cansaço, falta de concentração, esquecimentos, dores lombares e estresse foram apontados como queixas que também figuram como incômodos.

Com relação às atividades de cuidado à saúde dos usuários, o fato de não conseguirem resolver os problemas que as pessoas lhes apresentam e a preocupação com as necessidades de saúde das pessoas foram registradas como os que trazem mais angústia.

A contaminação do tempo livre também foi registrada na pesquisa, quando $77 \%$ dos trabalhadores responderam que levam trabalho para complementar em casa e $69 \%$ realizam trabalhos fora do horário habitual da Unidade, fato que tem trazido transtornos pessoais para $61 \%$ dos integrantes da equipe e em $69 \%$ contribuído para transtornos familiares. Além disso, $77 \%$ dos trabalhadores relataram que a população do território os procura no domicílio, fora do horário de serviço, principalmente em busca de orientações sobre o funcionamento da Unidade, para agendamento de consultas e marcação de exames e para a solicitação de receitas de medicamentos.

Sobrecarga de trabalho, baixos salários, falta de materiais e equipamentos, falta de reconhecimento profissional e a precariedade dos vínculos de trabalho foram identificados como principais agentes estressores.

Indagados sobre o grau de satisfação quanto ao trabalho desenvolvido, os integrantes da equipe revelaram que encontram-se satisfeitos, mas que as condições poderiam ser melhoradas, e ainda registraram: melhores salários, melhor divisão do trabalho entre a equipe, mais capacitações e treinamentos, aumento do número de profissionais para a Unidade, desprecarização dos vínculos de trabalho e reconhecimento profissional por parte do gestor, da equipe e também dos usuários.
Os trabalhadores também foram inquiridos sobre hábitos de vida que são influenciados pelo trabalho. Segundo os entrevistados, a carga de trabalho dificulta a realização de atividades de lazer em $38 \%$, as atividades com a família em $23 \%$ e o descanso em $39 \%$. Os dados consolidados também apontam que $61 \%$ não realizam caminhadas nem praticam exercícios físicos regularmente, $50 \%$ não realizam atividades de lazer e $54 \%$ não utilizam tempo livre para atividades pessoais.

Quanto à satisfação com o trabalho na ESF, os trabalhadores dividiram-se no registro de "muito satisfeito" (46\%) e "satisfeito, mas poderia melhorar" (54\%). Por fim, registrou-se, por $77 \%$ dos trabalhadores, a insatisfação com sua qualidade de vida.

Como nota-se, os resultados demonstram que, quando se referencia a própria saúde, o trabalhador/cuidador preocupa-se mais com problemas e agravos de saúde já instalados, cuja sintomatologia é que direciona a procura por cuidados de saúde. Desvelam, ainda, uma realidade preocupante: há indicativos de que o trabalhador/cuidador tende a negligenciar os aspectos preventivos e de promoção da própria saúde. Os sinais de sofrimento orgânico e psíquico também constituem registros da sobrecarga laborativa e da precariedade dos vínculos e das condições de trabalho.

O estudo aponta, assim, que merecem ser feitas reflexões sobre a saúde ocupacional na ESF, e que a prevenção e a promoção da saúde precisam ser 'exercitadas' pelos trabalhadores. Faz-se necessário, também, rever os caminhos da ESF sob a ótica da Saúde do Trabalhador, rumo à construção dos ambientes de trabalho humanizados e humanizadores.

\section{Conclusão}

Com relação aos resultados do estudo e respondendo à hipótese levantada no início, pode-se afirmar que os trabalhadores da ESF necessitam de cuidados e de um olhar diferenciado sobre as questões relacionadas à própria saúde.

O redesenho da divisão territorial das equipes já tem sido apontado como estratégia para considerar os fluxos de saúde e garantir a melhor organização e divisão das atividades desenvolvidas ${ }^{6}$. Fazem-se prementes, nesse sentido, considerações acerca da 'reorganização' e reestruturação do trabalho em saúde na ESF na construção de soluções mais humanas, valorizando-se as potencialidades e reconhecendo-se os limites e as suscetibilidades individuais.

O planejamento incipiente também favorece a sobrecarga, uma vez que realimenta o retrabalho e as ações desordenadas e desarticuladas ${ }^{6}$. Há que se lançar também diretrizes no sentido de suprir essa necessidade. 
Avançar na gestão da ESF, profissionalizando-a, dotando-a de instrumentos de monitoramento e avaliação contínuos, revela-se, também, como um caminho a ser trilhado.

A educação permanente dos trabalhadores/cuidadores, de modo a supri-los de tecnologias relacionais e instrumentais, tão demandadas pelo cotidiano das práticas e ações de saúde, merece atenção e deve compor as agendas da gestão municipal da saúde.

Além disso, buscar a ampliação das equipes da ESF, incorporando novos profissionais, deve ser alvo de consideração, já que a sobrecarga de trabalho elucida-se como um dos principais agentes estressores evocados pelos trabalhadores.

Tal questão, interpretada como onerosa por grande parte dos gestores municipais, deve ser reforçada com o reconhecimento das potencialidades da ESF na ampliação do acesso e na melhoria das condições de saúde e de vida das comunidades.

Evidentemente, os arranjos institucionais instituídos ao longo da implementação da ESF constituem elementos dificultadores do processo. Há, portanto, que se avaliar tais práticas e reverter as questões que lhes deram origem.

A prevenção e promoção da saúde precisam ser 'exercitadas' pelos trabalhadores da saúde. Deve-se, assim, rever tal caminho, rumo à construção de ambientes de trabalho humanizados, dignos, que valorizem a realização profissional, mas que não esqueçam que o cuidado em saúde envolve dois significados, que se inter-relacionam, quem cuida e quem é cuidado, e que a qualificação desse encontro expressa-se também, no cuidado consigo mesmo.

Não se pode negligenciar a constatação de que o espaço de produção da saúde seja também o da doença para os trabalhadores da saúde. Questões que denotam conflitos de interesses, como a produtividade em saúde, a organização e o dimensionamento dos processos produtivos em saúde, o exercício de poder entre os membros da equipe e também da equipe gestora, dentre outras, devem dar lugar à construção de políticas de saúde, as quais contemplem o trabalhador/cuidador da saúde e abordem suas necessidades e angústias.

Portanto, as repostas para tantas necessidades e prioridades não encontram suporte adequado apenas a partir de iniciativas e intervenções pontuais e desarticuladas. Somente uma rede social harmônica, estruturada a partir da integração de ações intersetoriais e interinstitucionais, pode favorecer a consolidação de políticas públicas saudáveis e fortalecer as capacidades dos indivíduos e da comunidade para a modificação dos fatores essenciais ecológicos, socioeconômicos, políticos, culturais, ocupacionais e comportamentais, que são condicionantes e determinantes do processo saúde-doença-cuidado.

\section{Referências}

1. Brasil. Ministério da Saúde. Secretaria de Assistência à Saúde Coordenação de Saúde da Comunidade. Saúde da família: uma estratégia para a reorientação do modelo assistencial. Brasília: Ministério da Saúde; 1997.

2. Brasil. Ministério da Saúde. Secretaria de Atenção à Saúde. Departamento de Atenção Básica. Política Nacional de Atenção Básica. Série Pactos pela Saúde 2006, n. 4. Brasília: Ministério da Saúde; 2006.

3. Nespoli G. A micropolítica do programa de saúde da família: um estudo de caso no território llha das Caieiras, Vitória-ES. [dissertação]. Rio de Janeiro: Programa de Pós-graduação em Saúde Coletiva, Instituto de Medicina Social da Universidade do Estado do Rio de Janeiro; 2002.

4. Mendonça AVM, Sousa MF. O PSF em Juazeiro: seus andares. Rio de Janeiro: Cebes; 2004.

5. Mendonça AVM, Sousa MF. Dez anos do PSF em Campina Grande: o sentir e o fazer - suas vozes. Rio de Janeiro: Cebes; 2004

6. Oliveira Neto FS. Gestão do Sistema Único de Saúde: olhares sobre a Saúde da Família em municípios do Espírito Santo- 1998-2007. [dissertação]. São Paulo, Programa de Pós-graduação em Gestão de Saúde e Meio Ambiente, Centro Universitário Senac; 2009.

7. Brasil. Ministério da Saúde. Departamento de Atenção Básica. Apresenta informações sobre evolução do credenciamento e implantação da Saúde da Família [Internet] [acesso em 2009 Set 15]. Disponível em: http:// dtr2004.saude.gov.br/dab/historico_cobertura_sf.php

8. Silva RC, Vilela RAG. A saúde da família nas mãos das "mulheres maravilhas": trabalho e sofrimento das agentes comunitárias de saúde sob a ótica da ergonomia. [monografia]. Piracicaba: Universidade Metodista de Piracicaba; 2006.

9. Franco TB. As redes na micropolítica do processo de trabalho em saúde. In: Pinheiro R, Mattos RA. Gestão em redes: práticas de avaliação, formação e participação na saúde. Rio de Janeiro: CEPESC-IMS/UERJLAPPIS; 2006.

10. Boff L. Saber cuidar: ética do humano - compaixão pela terra. Rio de Janeiro: Petrópolis; 1999.

11. Brasil. Ministério da Saúde. Secretaria de Gestão do Trabalho e da Educação na Saúde. Departamento de Gestão da Educação na Saúde. Curso de formação de facilitadores de educação permanente em saúde: unidade de aprendizagem - trabalho e relações na produção do cuidado em saúde. Rio de Janeiro: Ministério da Saúde/Fiocruz; 2005.

12. Schmidt MI, Duncan BB, Giugliani ERJ. Medicina ambulatorial: condutas de atenção primária baseadas em evidências. 3. ed. Porto Alegre: Artmed; 2004.

13. Gonçalves RJ, Soares RA, Troll T, Cyrino EG. Ser médico no PSF: formação acadêmica, perspectivas e trabalho cotidiano. Rev Bras Ed Médica. 2009; 33(3): 393-403.

14. Brasil. Conselho Nacional de Secretários de Saúde. Atenção Primária e Promoção da Saúde. Coleção Progestores - Para entender a gestão do SUS, 8. Brasília: CONASS; 2007.

15. Brasil. Ministério da Saúde. Fundação Oswaldo Cruz. Saúde da Família: avaliação da implementação em dez grandes centros urbanos: síntese dos principais resultados. 2. ed. atual. Brasília: Editora do Ministério da Saúde; 2005

16. SBMFC. Site oficial. O Título de Especialista em Medicina de Família e Comunidade. [Internet] [acesso em 2011 Set 15]. Disponível em: http:// www.sbmfc.org.br/default.asp?site_Acao=MostraPagina\&Paginald=14

17. Reis LB. Uma análise da dimensão ético-política do trabalho de agentes comunitários de saúde no município de Vitória. [dissertação]. Vitória: Programa de Pós-graduação em Psicologia, Universidade Federal do Espírito Santo; 2005

18. Merhy EE. Em busca do tempo perdido: a micropolítica do trabalho vivo em saúde. In: Merhy EE, Onocko R. Agir em saúde: um desafio para o público. 3. ed. São Paulo: Hucitec; 2007.

19. Oliveira RG, Grabois V, Mendes Júnior WV. Qualificação de gestores do SUS. Rio de Janeiro: EAD/Ensp; 2009.

20. Bellini MIB. Desenvolvimento do sujeito contemporâneo e saúde: algumas respostas possíveis. Centro Português de Investigação em História e Trabalho Social (CPIHTS). Estudos e documentos. [Internet] [acesso em 2011 Set 15]. Disponível em: http://www.cpihts.com/PDF02/ Mº20lsabel\% 20Bellini.pdf 
21. Backes DS, Erdmann AL. Humanizando o cuidado pela valorização do ser humano: resignificação de valores e princípios pelos profissionais de saúde. Rev Lat-Am Enf. 2007; 15(1): 34-41.

22. Merhy EE. Gestão da produção do cuidado e clínica do corpo sem órgãos: novos componentes dos processos de produção do cuidado em saúde: desafios para os modos de produzir o cuidado centrados nas atuais profissões. UFRJ. Linha de Pesquisa Micropolítica do Trabalho e o Cuidado em Saúde. [Internet] [acesso em 2009 Set 25]. Disponível em: http://www.medicina.ufrj.br/micropolitica/textos/gestao_da_producao do_cuidado.pdf
23. Pinheiro R, Mattos RA. Construção da integralidade: cotidiano, saberes e práticas em saúde. Rio de Janeiro: IMS-UERJ; 2003.

24. Pinheiro R, Mattos RA. Cuidado: as fronteiras da integralidade. Rio de Janeiro: IMS-UERJ; 2001.

25. Jerônimo Monteiro. Secretaria Municipal de Saúde. Sistema de Informação de Atenção Básica. Consolidado das famílias cadastradas. 2009.

26. Minayo MCS. O desafio do conhecimento: pesquisa qualitativa em saúde. 9. ed. São Paulo: Hucitec; 2006.

Anexo 1. Questionário semiestruturado desenvolvido para a coleta de dados da pesquisa

1 - Você se preocupa com sua saúde?
( ) Muito
( ) Pouco
( ) Muito pouco
( ) Não me preocupo
2 - Você acha que tem cuidado bem de sua saúde?
( ) Sim, cuido frequentemente
( ) Não, tenho deixado um pouco de lado
3 - 0 que você acha que atrapalha o cuidado com sua própria saúde?
( ) Falta de tempo
( ) Esquecimento
( ) Pressa

( ) Outro:

( ) Não tenho problemas com o cuidado com minha saúde

4 - Você:

( ) Se preocupa com a prevenção de possíveis problemas de saúde

( ) Só procura o serviço de saúde quando sente alguma coisa

( ) Não procura os serviços de saúde, porque não sente nada

5 - Você se lembra de ter aferido sua pressão arterial (PA) nos últimos:

a) Trinta dias ( ) Nenhuma

$$
\text { Vez(es) }
$$

b) Dois meses

$$
\text { ( ) Nenhuma }
$$$$
\text { Vez(es) }
$$

c) Seis meses

$$
\text { ( ) Nenhuma }
$$$$
\text { Vez(es) }
$$

d) Um ano

$$
\begin{array}{r}
\text { ( ) Nenhuma } \\
\text { Vez(es) }
\end{array}
$$

\section{6 - A PA foi ou não aferida porque:}

( ) Você sentiu-se mal e achou que poderia estar relacionado à alteração da PA

( ) Você tem por hábito aferir regularmente sua PA

( ) Não tenho costume de aferir a PA
( ) Considero que não é necessário aferir a PA

( ) Não tenho tempo para ficar aferindo a PA

( ) Não tenho me sentido mal e, por isso, não afiro a PA

7- Você tem costume de fazer exames de rotina?

( ) $\operatorname{Sim}$ ( ) Não

8- Porque você faz ou não exames de rotina?

( ) Considero importante fazer um check-up anual

( ) Me senti mal e foram solicitados exames

( ) Não tenho tempo para a realização de exames

9 - Quanto tempo faz que você não realiza exames de rotina?

( ) Menos de 3 meses

( ) Mais de 3 meses e menos de 6 meses

( ) Mais de 6 meses e menos de 1 ano

( ) Mais de um ano

( ) Mais de 2 anos

10 - Você já deixou de realizar procedimentos relacionados à sua saúde devido a questões relacionadas ao seu trabalho?

( ) $\operatorname{Sim}$ ( ) Não

0 que, por exemplo?

11 - E, com relação a sua família, também já aconteceram casos de você ter que adiar procedimentos com familiares devido ao trabalho?

( ) $\operatorname{Sim}$ ( ) Não

0 que, por exemplo?

E isso lhe deixa com sentimentos de culpa?

( ) $\operatorname{Sim}$ ( ) Não

12 - Você faz atualmente algum tratamento de saúde?

( ) $\operatorname{Sim}$ ( ) Não

Se afirmativo, qual (is)? 
Você sente que está destinando tempo e atenção adequados para cuidar deste(s) problema(s) de saúde?

( ) $\operatorname{Sim}$

( ) Não tenho destinado tempo e atenção necessários

( ) Não tenho problemas de saúde em tratamento

13 - Você considera que o trabalho na saúde traz:

( ) Mais desgaste emocional

( ) Mais desgaste físico

( ) Tanto desgaste físico como emocional

( ) Não traz desgaste físico nem emocional

Isso tem sido alvo de sua preocupação?

( ) $\operatorname{Sim}$

( ) Não me preocupo com isso

14 - Quantas vezes você computaria que tenha ficado triste ou aborrecido em virtude de problemas relacionados ao seu trabalho?

( ) Nunca fiquei triste ou aborrecido

( ) Poucas vezes

( ) Muitas vezes

( ) Fico sempre triste e aborrecido com o meu trabalho

15 - Das manifestações abaixo, assinale aquelas que com mais frequência você sente com relação ao seu serviço (pode marcar mais de uma alternativa):
( ) Raiva
( ) Impaciência
( ) Culpa
( ) Medo
( ) Angústia
( ) Confusão
( ) Nervosismo
( ) Irritação
( ) Choro

16 - Como trabalhador/cuidador da saúde você (pode marcar mais de uma alternativa):

( ) Fica angustiado por não conseguir resolver os problemas das pessoas

( ) Não se deixa abalar pelos problemas dos outros

( ) Sabe separar bem o que é o problema dos outros e os seus problemas

( ) Fica preocupado com as necessidades de saúde das pessoas

( ) Enxerga os problemas dos outros como se você com você ou alguém de sua família

17 - Você sente que é capaz de separar bem o que é de seu trabalho e o que é da sua vida com seus familiares?

( ) Sim, deixa as coisas relacionadas ao trabalho no setor de trabalho

( ) Sente que não consegue se desvincular das coisas do trabalho

( ) Outro:
18 - Você leva serviço para fazer em casa?

( ) $\operatorname{Sim}$

( ) Não

19 - Você realiza atividades de trabalho fora do horário normal?

( ) $\operatorname{Sim}$

( ) Não

Isso tem the atrapalhado na vida diária?

( ) Sim

( ) Não

Isso atrapalha a relação com familiares?

( ) $\operatorname{Sim}$

( ) Não

20 - As pessoas do seu território Ihe procuram em casa fora do horário de serviço?

( ) $\operatorname{Sim}$ ( ) Não

E você atende suas necessidades?

( ) Sim, faz o que está ao seu alcance

( ) Não, pede para procurar na Unidade no horário de serviço

Por quais causas as pessoas Ihe procuram nos horários fora de serviço?

21 - Quando você não consegue realizar alguma atividade programada em seu serviço você sente-se (pode marcar mais de uma alternativa):

( ) Culpado

( ) Com remorso

( ) Tem a sensação de que agiu errado

( ) Impotente

( ) Frustrado

( ) Outro:

22 - Você sente com que frequência os sintomas abaixo:

a) Insônia - ～( ) Frequente ( ) Pouco frequente ( ) Nunca

b) Cansaço -

( ) Frequente ( ) Pouco frequente ( ) Nunca

c) Dor de cabeça -

( ) Frequente ( ) Pouco frequente ( ) Nunca

d) Dor em Membros Inferiores - ( ) Frequente ( ) Pouco frequente ( ) Nunca

e) Palpitações - $\quad$ ( ) Frequente ( ) Pouco frequente ( ) Nunca

f) Estresse - ( ) Frequente ( ) Pouco frequente ( ) Nunca

g) Falta de concentração - ～( ) Frequente ( ) Pouco frequente ( ) Nunca

h) Esquecimentos - $\quad$ ( ) Frequente ( ) Pouco frequente ( ) Nunca

i) Problemas sexuais - ( ) Frequente ( ) Pouco frequente ( ) Nunca

j) Dores lombares - $\quad$ ( ) Frequente ( ) Pouco frequente ( ) Nunca

l) Dor cervical - ( ) Frequente ( ) Pouco frequente ( ) Nunca

m) Dor no estômago - ( ) Frequente ( ) Pouco frequente ( ) Nunca

Você toma algum tipo de remédio com frequência para estes problemas?

( ) Sim. Qual (is)?

( ) Não tomo remédio 
23 - Com que frequência se sente depressivo?

( ) Diariamente

( ) Frequente

( ) Pouco frequente

( ) Nunca

Isso the incomoda ou interfere no seu dia-a-dia?

( ) $\operatorname{Sim}$

( ) Não

( ) Não me incomoda

Você toma algum remédio para este problema?

( ) Sim. Qual?

( ) Não tomo remédio

24 - Com que frequência se sente ansioso?

( ) Diariamente

( ) Frequente

( ) Pouco frequente

( ) Nunca

Isso the incomoda ou interfere no seu dia-a-dia?

( ) $\operatorname{Sim}$

( ) Não

( ) Não me incomoda

Você toma algum remédio para este problema?

( ) Sim. Qual?

( ) Não tomo remédio

25 - 0 que Ihe incomoda mais no seu trabalho? Marque apenas uma alternativa que the incomoda mais:

( ) Sobrecarga de trabalho

( ) Relações conflituosas com a equipe

( ) Baixo salário

( ) Relações conflituosas com usuários

( ) Precariedade do vínculo de trabalho

( ) Más condições de trabalho

( ) Falta de material para trabalhar

( ) Falta de reconhecimento profissional

( ) Reclamações dos usuários quanto ao seu trabalho

( ) Reclamações da própria equipe quanto ao seu trabalho

26 - 0 que the incomoda mais no seu trabalho? (Agora enumere em ordem decrescente as alternativas que Ihe incomodam, ou seja, a número 1 lhe incomoda mais, a número 2 Ihe incomoda menos, a 3 lhe incomoda, um pouco menos etc. As alternativas que não Ihe incomodarem deixe em branco):
( ) Sobrecarga de trabalho
( ) Relações conflituosas com a equipe
( ) Baixo salário
( ) Relações conflituosas com usuários

( ) Precariedade do vínculo de trabalho

( ) Más condições de trabalho

( ) Falta de material para trabalhar

( ) Falta de reconhecimento profissional

( ) Reclamações dos usuários quanto ao seu trabalho

( ) Reclamações da própria equipe quanto ao seu trabalho

27 - Qual o grau de satisfação que você aplicaria para com o seu trabalho:

( ) Estou muito satisfeito com o meu trabalho

( ) Estou satisfeito, mas poderia melhorar

( ) Estou insatisfeito com o trabalho

0 que você acha que poderia ser feito para melhorar suas condições de trabalho?

28 - Você considera que sua carga de trabalho the impede de realizar (pode assinalar quantas alternativas quiser):

( ) Atividades de lazer

( ) Descansar

( ) Atividades com a família

( ) Outras atividades. Citar:

29 - Você:

a) Pratica caminhadas ou faz exercícios físicos regularmente - ( ) Sim ( ) Não

b) Faz atividades que considera lazer - ( ) Sim （ ) Não

c) Está satisfeito com sua capacidade de dar apoio aos outros - ( ) Sim ( ) Não

d) Utiliza tempo livre para você - ( ) Sim （ ) Não

e) Está satisfeito com sua qualidade de vida - ( ) Sim ( ) Não

30 - Quais atributos você considera essenciais aos trabalhadores/cuidadores da saúde: (pode marcar mais de uma alternativa)
( ) Esperança
( ) Fé
( ) Paciência
( ) Força de vontade
( ) Amor
( ) Carinho
( ) Solidariedade
( ) Outros: 